\title{
Laparoscopic dissection of the intramural ureter to repair a complete transection of the distal ureter: Initial experience with a new minimally invasive technique that preserves the anatomy of the urinary tract
}

\author{
Alvaro Juarez-Soto, MD; ; Jose Miguel Arroyo-Maestre, MD;* Manuel Soto-Delgado, MD;* \\ Pastora Beardo-Villar, MD; ${ }^{*}$ Miguel Angel Arrabal-Polo, MD; Francisco Miguel Sánchez-Margallo, MD
}

*Urology Department, Hospital de Jerez, Cadiz, Spain; ‘Surgery Department, Faculty of Medicine, Granada University, Granada, Spain; §Center for Minimally Invasive Surgery Jesus Usón, Caceres, Spain

Cite as: Can Urol Assoc J 2014;8(5-6):e366-70. http://dx.doi.org/10.5489/cuaj.1699 Published online May 21, 2014.

\begin{abstract}
We report 2 patients with ureteral injury after a simple total laparoscopic hysterectomy for uterine myoma with a complete resection of the distal ureter. One patient had unilateral injury and the other 2 patients had bilateral injury. The surgical laparoscopic repair procedure was carried out 3 to 5 days after the injury. Surgery involved intramural dissection of the distal ureteral stump to expose at least $1 \mathrm{~cm}$ of the ureter, percutaneous ureteral stent placement, elimination of tension between the proximal ureter and the dissected distal stump, end-to-end anastomosis, and reinsertion of the distal ureter into the bladder muscle layer, which was previously dissected for the anastomosis.
\end{abstract}

\section{Introduction}

latrogenic ureteral injury, either complete or partial, comprises $75 \%$ of cases of ureteral trauma. Distal ureteral injury is more common than injuries affecting the proximal ureter; in some cases, ureteral injury goes unnoticed and later presents as stenosis and hydronephrosis., ${ }^{1,2}$ Gynecological and urological procedures are most often associated with a ureteral injury. In gynecologic surgery, ureteral injury occurs in $0.1 \%$ to $1.5 \%$ of procedures for benign pathological conditions and up to $5 \%$ of oncologic procedures. ${ }^{2}$ The incidences of ureteral injury are as follows: $0.03 \%$ to $2 \%$ in abdominal hysterectomy, $0.02 \%$ to $0.5 \%$ in vaginal hysterectomy, $0.2 \%$ to $6 \%$ in laparoscopic hysterectomy, $1.7 \%$ to $3 \%$ in urogynecological procedures, and $4.4 \%$ in Wertheim's hysterectomy. ${ }^{2}$ The use of laparoscopic surgery in gynecology has increased the number of ureteral injuries. Ureteral injuries from gynecological procedures account for up to $64 \%$ of the injuries, with the remaining injuries due to laparoscopic general surgery and laparoscopic urologic surgery. ${ }^{1}$

The treatment of ureteral injuries differs depending on the location of the injury. ${ }^{3}$ In the distal ureter, where most injuries occur during gynecologic procedures, ${ }^{4}$ treatment depends on the diameter of the injury. If the injury transects less than $50 \%$ of the ureter, a ureteral stent is placed. If the injury is greater than $50 \%$ of the diameter, or if there is devascularization, surgery is then indicated. ${ }^{1}$ If surgery is needed, a ureteral reimplant is recommended as the first-line treatment for lower ureteral injuries. ${ }^{1}$

\section{Case reports}

We report 2 patients with complete ureteral injury of the nonintramural distal portion of the ureter resulting from gynecological surgery. One patient had unilateral injury and the other patient had injuries to both ureters. In all cases, the injury was caused by a 5-mm blunt tip sealer and divider device. Two patients underwent a simple total laparoscopic hysterectomy for uterine myoma. In one case, there was complete injury of the right distal ureter, and in the other case, there was complete injury of both distal ureters. In both cases, the ureteral injury was identified after the gynecologic surgery because of symptoms of peritonitis, including fever, malaise, and the presence of urine upon drainage. The diagnosis was confirmed by intravenous urography, noting a lack of continuity at the distal ureter in all cases (Fig. 1, Part A). Immediately after the diagnosis, that there were no signs of infection and a ureteral repair was performed using laparoscopic surgery. The surgeries involved a dissection of the distal ureteral stump with end-to-end anastomosis instead of performing ureteral reimplantation. All cases of anastomosis had satisfactory results with functional recovery, maintenance of function 6 months after surgery, and absence of complications (Table 1 ). 


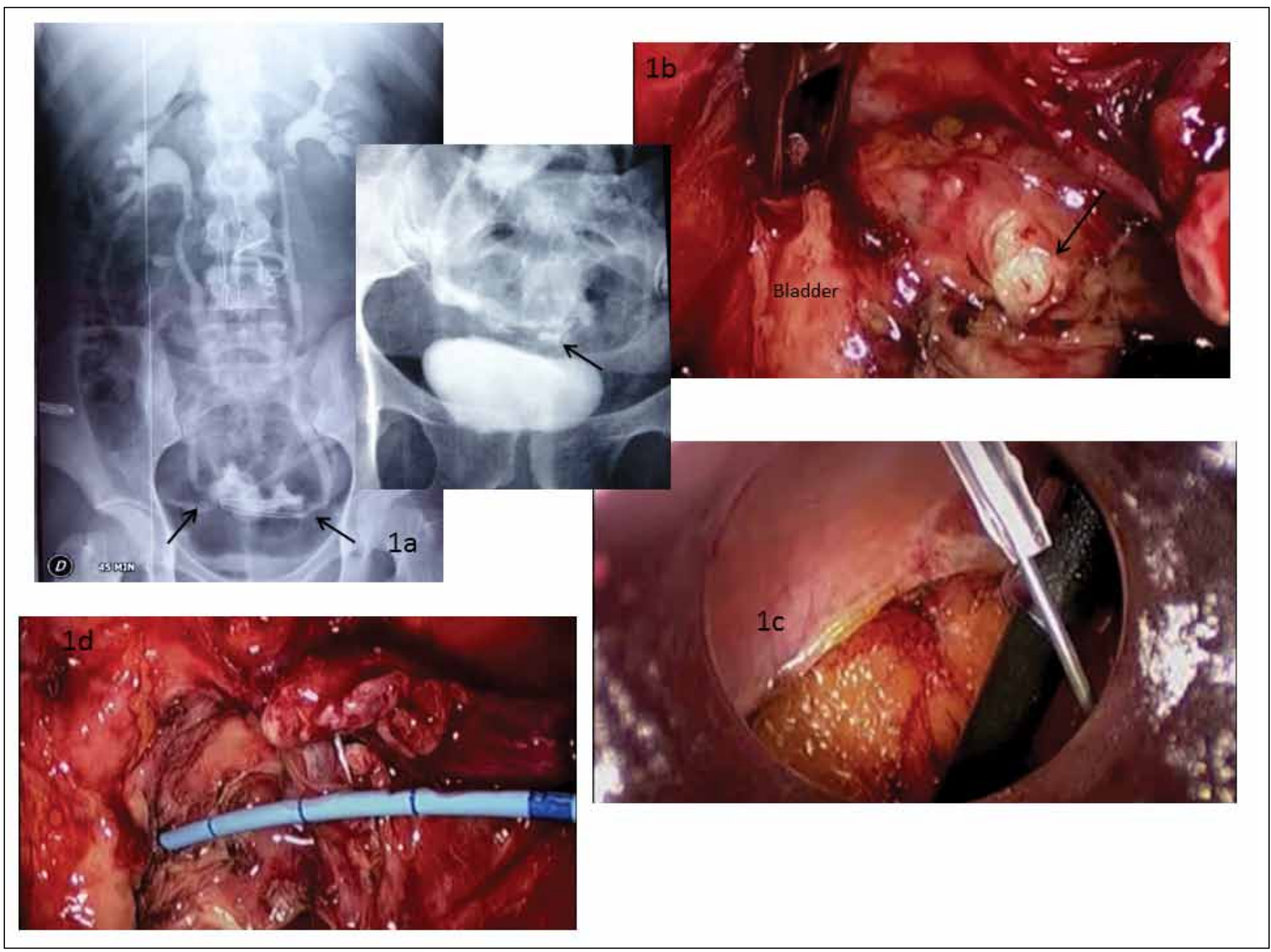

Fig. 1. Illustrating a discontinuity in the right ureter of patient 1 on urography, compatible with a complete distal ureteral resection and contrast extravasation. In patient 2, the resection was complete and bilateral at the distal level with peritoneal extravasation of contrast. In Part B: we see the stump of the right distal ureter and bladder. In Part C: we introduced an Abbocath No. 14 percutaneously for catheterization of the distal stump and subsequent positioning of the ureteral stent using a flexible guidewire, Part D.

\section{Surgical technique}

Prior to performing the surgery in humans, we performed experimental surgeries in a porcine model, simulating the conditions of an iatrogenic lesion of the non-intramural distal ureter. We verified the feasibility and reproducibility of the technique and found no complications. This phase of experimental surgery was performed at the Center for Minimally Invasive Surgery Jesus Uson (CCMIJU, based on its initials in Spanish) in Caceres, Spain. We placed the patient in the lumbotomy position with a dorsal tilt of 15 degrees and inserted 4 abdominal trocars. The first 12-mm trocar was placed in the paraumbilical-external line of the rectus abdominal region, the second and third trocars were placed in the ipsilateral iliac fossa and hypochondrium, and the fourth trocar was placed in the posterior axillary line. After dissection, we identified the complete ureteral injury and then the distal ureteral stump (Fig. 1, part B). We also used a flexible cystoscope via the retrograde route in case the injury could not be reached by laparoscopy. Once the distal end was located, we performed an abdominal puncture using an Abbocath No. 14, introducing a 0.035" guidewire (Boston Scientific, Jagwire) through the distal ureter until it was placed inside the bladder (Fig. 1, parts $C$ and D). To facilitate dissection of the ureter, we passed a 10 to $12-\mathrm{Fr}$ ureteral catheter over the guidewire so that the wire would remain in the bladder with its proximal end in the pelvic cavity. We then released the distal ureter along its intramural course (Fig. 2, parts A, B and C) using scissors, LigaSure (Covidien), and a Maryland dissector, until a segment of about $1 \mathrm{~cm}$ was obtained (Fig. 2, part D). We then checked that both the distal and proximal ends of the ureter could 


\begin{tabular}{|c|c|c|}
\hline & Patient 1 & Patient 2 \\
\hline Age & 46 & 38 \\
\hline Ureteral injury (number cases) & Right ureter (1) & Bilateral ureter (2) \\
\hline Ginecologic surgery & $\begin{array}{l}\text { Laparoscopic total simple histerectomy due } \\
\text { to myoma }\end{array}$ & $\begin{array}{l}\text { Laparoscopic total simple histerectomy due to } \\
\text { myoma }\end{array}$ \\
\hline Time from injury to reconstruction & 5 days & 3 days \\
\hline Time of laparoscopic reconstruction & 130 minutes & 295 minutes \\
\hline Complications after reconstruction & Feber on 10th day & No; blood transfusion due to megaloblastic anemia \\
\hline Time of drainage & 10 days & 6 days \\
\hline Time of bladder catheter & 15 days & 12 days \\
\hline Time of ureteral stent & 32 days & 28 days \\
\hline Control Urography & 6 months and 2 years later: Normal function & 6 months later: Normal function \\
\hline
\end{tabular}

be joined together without tension. A 4.8-Fr ureteral stent was introduced percutaneously and then placed over the flexible guidewire to be inserted into the bladder (Fig. 3, part A), leaving the proximal part of the J stent in the pelvic cavity. Once the distal end of the stent was in place, the flexible guidewire was removed. Then, the guidewire was reintroduced through one of the drain holes of the ureteral stent to rectify the proximal J (Fig. 3, part B) and to lift it up through the proximal end of the ureter to the renal cavity. After completing this step, we performed an end-to-end suture of the ureter with 5 to 7 isolated stitches of resorbable material 4/0 (Fig. 3, part C). To complete the procedure, we inserted the dissected distal ureteral segment within the bladder muscle layer. The drain was removed between the 6th and 10th postoperative days, the urinary catheter was removed between the 12 th and 15 th postoperative days, and

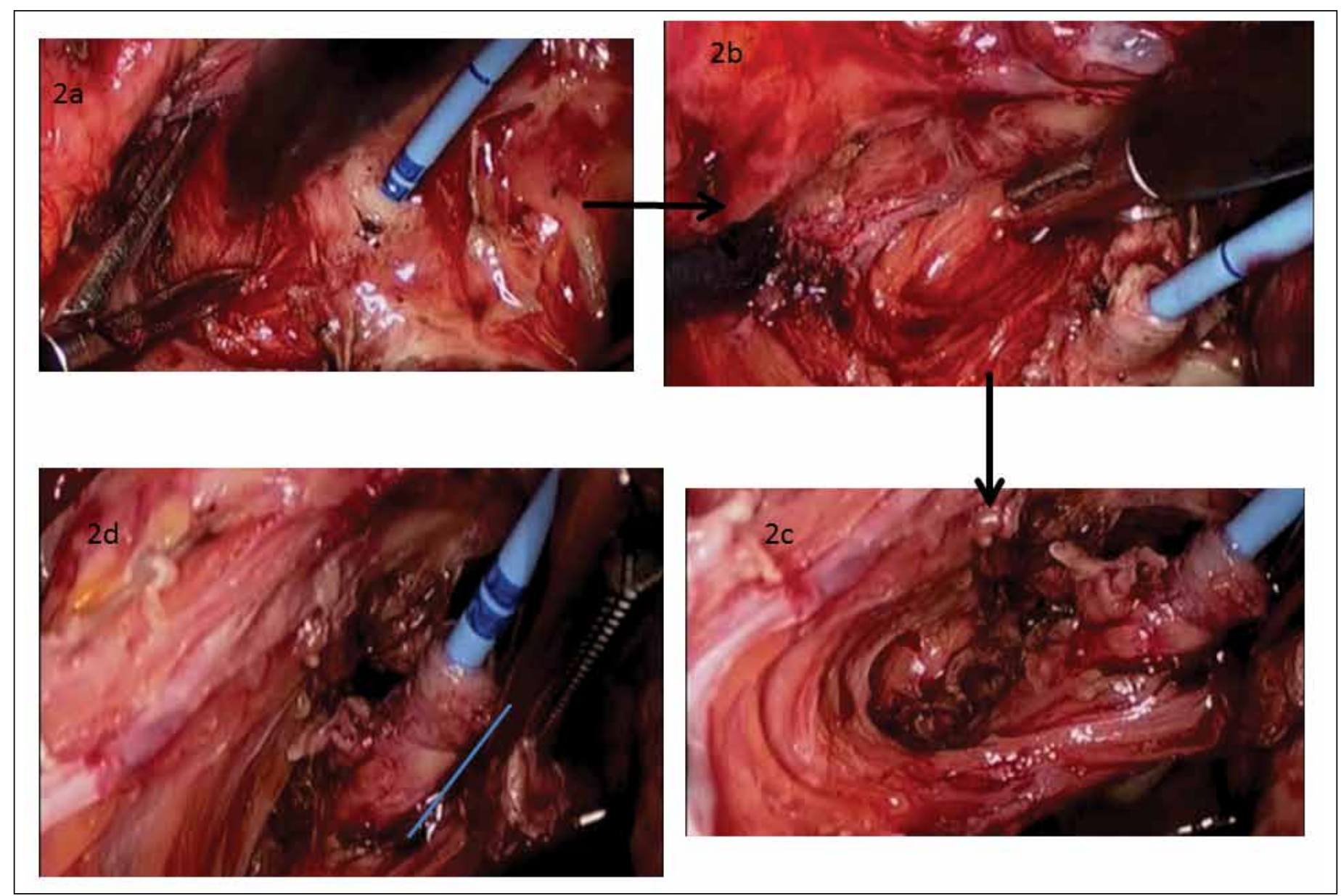

Fig. 2. In Part A, we began dissecting the intramural ureter, first the medial zone and then the anterior (Part B) and lateral zones (Part C), until we obtained at least $1 \mathrm{~cm}$ of free and mobile intramural ureter (Part D). This segment was used in the subsequent anastomosis. 


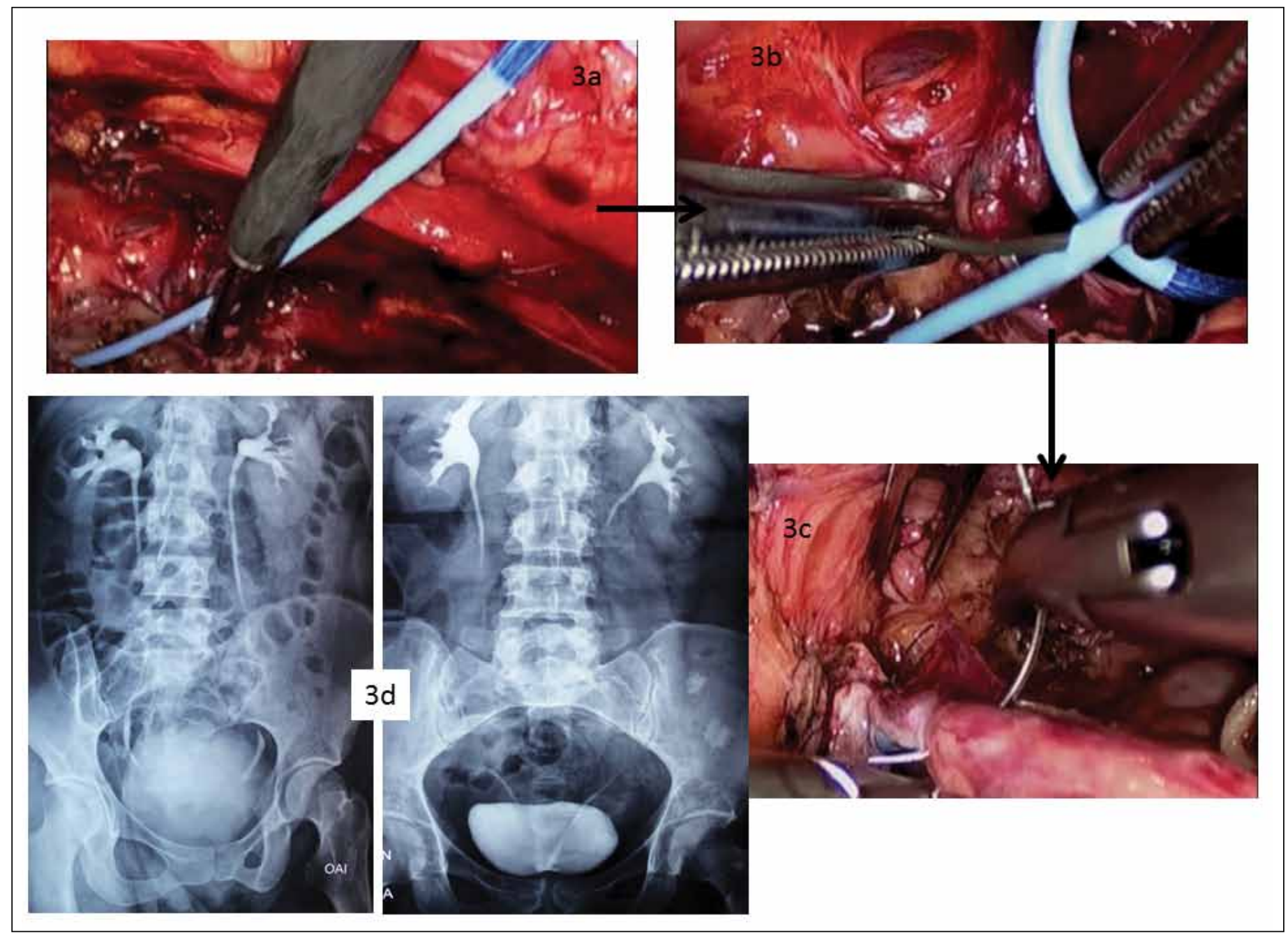

Fig. 3. In Part A, we position the double J ureteral stent in the distal stump. After rerouting the stent with a flexible guidewire (Part B), we positioned the proximal end. After placing the ureteral stent, the end-to-end anastomosis was completed (Part C) while ensuring that there was no ureteral tension. Part D shows the results at 2 years (patient 1) and 6 months (patient 2) after reconstructive surgery, without leakage or stenosis and with functional kidney status.

the ureteral stent was removed at 4 weeks. In patient 1, we observed good renal function with no signs of stenosis or contrast leakage 2 years after the surgery. In patient 2, we observed good renal function without stenosis or leakage 6 months after the surgery (Fig. 3, part D).

\section{Discussion}

Laparoscopic treatment of ureteral injuries appears to be the method of choice due to its good results. ${ }^{2}$ When there is complete injury of the distal ureter, direct ureteral reimplantation or a psoas-bladder or Boari-flap hitch procedure is usually performed to ensure ureterovesical continuity. ${ }^{1,5}$ This type of surgical treatment with ureteroneocystostomy often requires ureteral re-implantation to control the physiological function of the ureterovesical junction, ${ }^{5}$ a procedure that extends the operating time and increases morbidity. In general, when complete injury of the ureter occurs, a repair is performed to spatulate the ureter by placing a ureteral stent and suturing end-to-end, providing there is a ureteral stump that can be used for reanastomosis. ${ }^{3,6,7}$ In our surgical technique, we dissected a segment of the intramural ureter, which provided us with a distal segment that was large enough to accommodate a ureteral stent and allow for end-to-end suturing without tension. We placed the ureteral stent percutaneously, sliding it over a flexible guide that was inserted through an Abbocath in the distal ureteral stump. This approach allowed us to position the distal end of the stent intravesically and then redirect the guide to the proximal end of the ureter to position the stent in the kidney. This method allowed us to place the ureteral stent without changing the patient's position during laparoscopy, which has been done by other authors. ${ }^{8}$ Ureteroureteral anastomosis, with dissection of the distal intramural ureter to obtain 
a distal stump of more than $1 \mathrm{~cm}$, has not been previously described in the literature because, in most cases, a ureteral re-implantation has been performed when there is no portion of the distal ureter that is large enough for end-to-end anastomosis. ${ }^{2,3,9}$ Intramural ureter dissection using a ureteral stent for guidance is simple and straightforward; we can collect up to $1 \mathrm{~cm}$ of viable and healthy distal ureter, facilitating endto-end anastomosis. Our technique also reduces morbidity and surgical time compared to other techniques, including direct re-implantation of the ureter into the bladder, ${ }^{2,3,10}$ and eliminates the need for an anti-reflux mechanism.

\section{Conclusion}

We believe that preserving the physiological and anatomical arrangement of the urinary tract should be the first treatment option, even when the injury occurs in the distal portion of the ureter. This method will allow for better monitoring and treatment in the future with less morbidity. Our experience with this technique is limited. However, due to our good results in this early phase, with no complications, such as fistulas, strictures, or infections, we think that this procedure merits further investigation to evaluate its possibility as a first-line treatment.

Competing interests: Dr. Juarez-Soto, Dr. Arroyo-Maestre, Dr. Soto-Delgado, Dr. Beardo-Villar, Dr. Arrabal-Polo and Dr. Sánchez-Margallo all declare no competing financial or personal interests.
This paper has been peer-reviewed.

\section{References}

1. Abboudi H, Ahmed K, Royle J, et al. Ureteric injury: A challenging condition to diagnose and manage. Nat Rev Urol 2013;10:108-15. hittp://dx.doi.org/10.1038/nrurol.2012.254

2. De Cicco C, Ussia A, Koninckx PR. Laparoscopic ureteral repair in gynecological surgery. Curr Opin Obstet Gynecol 2011;23:296-300.

3. De Cicco C, Schonman R, Craessaerts M, et al. Laparoscopic management of ureteral lesions in gynecology. Fertil Steril 2009;92:1424-7. http://dx.doi.org/10.1016/ifertnstert.2008.08.021

4. De Cicco C, Ret Dávalos ML, Van Cleynenbreugel B, et al. latrogenic ureteral lesions and repair: A review for gynecologists. J Minim Invasive Gynecol 2007;14:428-35. http://dx.doi.org/10.1016/i. jmig.2007.01.003

5. Nú-ez Mora C, García Mediero JM, Cabrera PM, et al. Treatment of distal ureteral stenosis using laparoscopic ureterovesical reimplantation. Actas Urol Esp 2011;35:31-6.

6. Choi KM, Choi JS, Lee JH, et al. Laparoscopic ureteroureteral anastomosis for distal ureteral injuries during gynecologic laparoscopic surgery. J Minim Invasive Gynecol 2010;17:468-72. http://dx.doi. org/10.1016/i.mig.2010.03.002

7. Liu CY, Kim JH, Bryant JF. Laparoscopic ureteroureteral anastomosis on the distal ureter. J Am Assoc Gynecol Laparosc 2011;8:412-5. http://dx.doi.org/10.1016/S1074-3804(05)60341-6

8. Brichart N, Prezelin Y, Celhay 0 , et al. Novel method for placement of a ureteral stent during laparoscopic ureteroureterostomy. J Endourol 2008;22:2411-2. http://dx.doi.org/10.1089/end.2008.0153

9. Symons S, Kurien A, Desai M. Laparoscopic ureteral reimplantation: A single center experience and literature review. J Endourol 2009;23:269-74. http://dx.doi.org/10.1089/end.2008.0266

10. Manoucheri E, Cohen SL, Sandberg EM, et al. Ureteral injury in laparoscopic gynecologic surgery. Rev Obstet Gynecol 2012;5:106-11.

Correspondence: Dr. Miguel Angel Arrabal-Polo. Camino de ronda street, 143, 4F. Postal zip: 18003. Granada. Spain; arrabalp29@gmail.com 